\title{
La instauración de un dispositivo lingüístico cratiliano como fundamento de un método de creación poética: la palabra fundacional de Francis Ponge
}

\author{
Begoña CAPLLONCH BUJOSA \\ Universitat Pompeu Fabra \\ Departamento de Humanidades \\ begona.capllonch@upf.edu
}

Recibido: 8 de septiembre de 2010

Aceptado: 13 de octubre de 2010

\begin{abstract}
RESUMEN
En este artículo examinamos el método de creación poética que llevó a cabo Francis Ponge y que supuso la instauración de un dispositivo lingüístico equiparable al de la tesis naturalista del Crátilo platónico, por lo que argumentaremos, a su vez, la viabilidad de la motivación del signo lingüístico en el lenguaje poético en virtud de que haría inteligible, más por revelación que por significación, el universo imaginario al que el poema habría dado aliento bajo el auspicio de la utópica función primigenia de la palabra en tanto que fundadora de la realidad a la que da nombre.
\end{abstract}

Palabras clave: Ponge, cratilismo, motivación sígnica, nomenclatura, método metalógico.

L'instauration d'un dispositif linguistique cratyléen sur la base d'une méthode de création poétique: la parole fondatrice de Francis Ponge

\section{RESUME}

Dans cet article nous examinons la méthode de création poétique suivie par Francis Ponge, et qui a supposé l'instauration d'un dispositif linguistique rappelant la thèse naturaliste du Cratyle platonicien. Aussi, nous défendons la motivation du signe linguistique dans le langage poétique en nous basant sur l'idée que cette motivation rendrait intelligible, par révélation plus que par signification, l'univers imaginaire fondé par le poème. Le principe légitimant cette conception est la soi-disante fonction originaire de la parole, celle-ci étant envisagée en tant qu'instrument fondateur de la réalité nommée.

Mots clés: Ponge, cratylisme, motivation du signe, nomenclature, méthode métalogique.

The founding of a linguistic Cratylean device as the basis of a method of poetic creation: Francis Ponge's foundational word

\begin{abstract}
The present article examines Francis Ponge's method of poetic creation, which constituted a linguistic device similar to the naturalistic thesis found in Plato's Cratylus. Thus, we will argue for the plausibility of the motivation of the linguistic sign within poetic language, on the basis that it would render more intelligible - by means of revelation rather than signification - the imaginary universe
\end{abstract}


created by the poem. This conception is based on the principle of the utopian primeval function of the word as the founder of the reality it names.

Key words: Ponge, cratylism, sign motivation, nomenclature, metalogic method.

Sumario: I. Motivación y convención en el signo lingüístico: ontología y epistemología. II. Un método para una poética: la méthode métalogique y la parole à l'état naissant. III. El fundamento lingüístico de la poética pongeana: la lengua como nomenclatura. IV. Sobre la doble direccionalidad de la noción motivada (conceptacle). Ejemplos metalógicos.

"La chose est son nom »

J. Derrida, Signéponge

\section{Motivación y convención en el signo lingüístico: ontología y epistemología.}

En su ensayo "Proust et les noms" (1967), Barthes se preguntaba, al advertir en el trazado onomástico de $\dot{A}$ la recherche que los nombres propios alcanzaban la dimensión semántica de los comunes al superar con creces su condición indiciaria para desarrollarse descriptiva y significativamente,

s'il n'est pas plus ou moins consciemment présent dans tout acte d'écriture et s'il est vraiment possible d'être écrivain sans croire, d'une certaine manière, au rapport naturel des noms et des essences: la fonction poétique, au sens le plus large du terme, se définirait ainsi par une conscience cratyléenne des signes et l'écrivain serait le récitant de ce grand mythe séculaire qui veut que le langage imite les idées et que, contrairement aux précisions de la science linguistique, les signes sont motivés (Barthes, 2004: 130).

En efecto, todo escritor funda con la palabra el universo imaginario al que su obra se refiere; y en muchos casos $-\mathrm{y}$, particularmente, en el ámbito de la creación poética-, se sirve de la motivación sígnica para conferir credibilidad a ese mundo (re)creado. Pero cabría preguntarse hasta qué punto, desde la perspectiva de la ciencia lingüística, podríamos hablar de verdadera motivación, dado que, a priori, un planteamiento naturalista en el que las palabras se asemejarían a los objetos por ellas designadas contradeciría el postulado fundamental de la lingüística moderna: el de la convencionalidad de los signos. Sin embargo, no habría lugar para tal contradicción, porque las propiedades que Saussure atribuyó al signo lingüístico (arbitraire, négatif, biface) deben considerarse con respecto a la concepción de lengua como sistema y desde el enfoque abstracto de una propuesta inmanente y descriptiva -que no trascendente e interpretativa-, por lo que no de un modo ineludible habría de colisionar esa modulación semántica a la que podría verse sometida una unidad de la lengua en un contexto de creación literaria, con la descripción estructural y sistemática de dicha unidad. 
Cuando Saussure desarrolló la tesis sobre la arbitrariedad del signo esbozada por el lingüista norteamericano William D. Whitney ${ }^{1}$, estaba aludiendo no a la relación que habría de vincular un signo -como entidad bifronte- a la realidad extralingüística a la que éste designaría, sino a la establecida entre un significado y su correspondiente significante; aunque sin duda el autor era consciente de la permeabilidad del sistema lingüístico con relación al mundo representado, puesto que señalaba, como posibles excepciones a la arbitrariedad, las motivaciones onomatopéyicas; pero también en estos casos apuntaba una cierta convencionalidad, pues lo refrendaba con el hecho de que diferentes lenguas explicitan mediante muy distintas formas unos mismos sonidos (Saussure, 1974: 101-102). Sin embargo, lo que cabe precisar es que, cuando Saussure mencionaba ciertos tipos de motivación, se refería únicamente a las relaciones de carácter intralingüístico, es decir, a las que podrían deducirse, por ejemplo, de los procesos derivativos ${ }^{2}$; y así como restringía la motivación a las relaciones de parentesco entre los mismos signos, la cuestión de la arbitrariedad la evaluaba siempre con respecto al vínculo entre la realidad y el lenguaje. La propuesta del ginebrino, en suma, se situaba al margen de lo real empírico o psíquico y con la finalidad de secundar su propósito de hacer de la lengua, considerada en sí misma y por sí misma, un objeto autónomo de estudio, es decir: no presuponiéndola un medio de indagación de la naturaleza ontológica de la realidad, sino equiparándola a cualquier otra materia susceptible de análisis científico. Por lo tanto, si bien el marco lingüístico saussureano era plenamente coherente con los principios sobre los que se cimentaba, no cabría esperar que también argumentase las posibles recreaciones que, con respecto a su alcance semántico, desarrollan las unidades de la lengua con relación al universo extralingüístico (real o ficticio) que podrían representar.

Así pues, las reservas para con los postulados de Saussure en lo que concierne a la descripción del mundo no tendrían pertinencia alguna, dado que la tesis de la arbitrariedad se habría juzgado impropiamente como "une proposition sur l'origine" cuando, lejos de tratarse de una "thèse ontologique", no era sino "un principe épistémologique" (Schaeffer, 1980: 188). Y de ahí que la propuesta del ginebrino no debiera coligarse con el planteamiento que conduciría a la distinción que establecieron los antiguos griegos entre la tesis naturalista y la convencionalista, porque Saussure no pretendía desentrañar el ser el lenguaje con respecto a la esencia misma de la realidad - cuya naturaleza, en definitiva, ignoramos-, sino el funcionamiento de la lengua en tanto que sistema de signos que nos permite acceder a ella desde su representación convencional. Y ello pese a la paradoja que supone el

${ }^{1}$ Para un esbozo de las posibles líneas precursoras del pensamiento saussureano, vid.: KoERNER, E. F. K. (1982): Ferdinand de Saussure. Génesis y evolución de su pensamiento en el marco de la lingüistica occidental. Contribución a la historia y a la teoría de la lingüistica, trad. de G. García Montaño. Gredos, Madrid, 405-447.

${ }^{2}$ Así lo ilustra el siguiente párrafo extraído del Cours: "vingt est immotivé, mais dix-neuf ne l'est pas au même degré, parce qu'il évoque les termes dont il se compose et d'autres qui lui sont associés, par exemple dix, neuf, vingt-neuf... [...]. Il en est de même pour poirier, qui rappelle le mot simple poire et dont le suffixe -ier fait penser à cerisier, pommier, etc." (Saussure, 1974: 181). 
no poder elucubrar en torno a lo real factual o imaginario desde una perspectiva no lingüística, dado que ésta sería, por lógica, inexpresable.

En consecuencia, el hecho de que muchos poetas ensayen la motivación sígnica no supondría la impugnación de los principios fundamentales por los que se rige la descripción lingüística, porque, en verdad, no compete al poeta el tener que ilustrar la coherencia del sistema de la lengua. En todo caso, el desarrollar, en la medida de sus intereses y de su facultad creadora, la capacidad expresiva, representativa e, incluso, demiúrgica del lenguaje, porque éste no es sólo el instrumento mediante el que nos representamos simbólicamente el mundo, sino el medio de que disponemos para recrearlo desde una perspectiva inédita, o bien para fundar todos los posibles ficticios. Y es por este motivo por el que, con frecuencia, la teoría del lenguaje poético motivado "retombe donc en fait de nouveau dans l'ontologie: elle implique une théorie des choses et il n'est pas étonnant qu'elle se présente souvent sous la forme d'une théorie de l'origine" (Schaeffer, 1980: 189); y sobre esta teoría del origen se cerniría, en efecto, la "nostalgie d'une relation directe entre des signes et des choses" (Gefen, 2002: 214) al asociarse, el acto de la escritura, al de la creación fundacional. Así pues, en caso de que un poeta estableciese etimologías para justificar el vínculo entre un objeto y su apelativo -tal y como sucederá en la obra de Ponge-, no debería esperarse que esas formas etimológicas respondieran fehacientemente a las leyes de la gramática histórica, puesto que, en realidad, "elles sont secondées par la tradition biblique de la nomination divine et du calembour créateur dans le paradis adamique du premier langage" (Little, 1992: 35).

No obstante, lo que cabe destacar es que, si la poesía puede recrear un planteamiento cratiliano, es porque, precisamente, el significado de las palabras se rige bajo el principio de la convencionalidad, dado que la emancipación del signo de su carácter convencional no podría llevarse a cabo mediante una total desvinculación entre signans y signatum, sino a partir del establecimiento de otro nuevo sistema de reglas al que debería sujetarse el discurso para alcanzar su cometido. El poeta, pues, sobrepondría a los sentidos convencionales el criterio semántico de la motivación mediante un específico trabajo de elección léxica y de configuración textual, porque lo que habría cambiado no sería el funcionamiento de la lengua, sino la relación entre el aspecto sensible del signo y su dimensión inteligible. Y ello al objeto de que pudieran ser convocadas las particularidades de ese universo imaginario creado lingüísticamente, es decir: no a pesar de la convencionalidad, sino gracias al sedimento de los significados constantes a partir de los que podría obrar la catálisis motivadora.

De hecho, una realidad poética puede conformarse únicamente como una sensación o como un complejo imaginativo de cariz abstracto, y de ahí la idoneidad de que, a través de la motivación y por diferentes recursos (fonéticos, caligráficos o propiamente de asociación semántica), se establezca una identificación por semejanza entre lo que conocemos de nuestro mundo experiencial, y lo que habría sido creado ad hoc por el poema, ya que se produciría un efecto de inmediatez intelectiva entre lo representado y la representación (entre la figura y la entidad figurada). La semejanza, pues, dotaría de credibilidad a ese nuevo universo de referencia; y cobraría especial relevancia en una obra como la de Ponge, dado que 
al proponerse este autor redefinir (refaire) la realidad empírica soslayando la imagen conceptualizada que de ella tenemos, necesitaba rehuir la convención para significar por mostración. Por este motivo su obra fundamental se titulaba Le Parti pris des choses (1942), puesto que para operar esa redefinición del mundo tuvo que proponer una nueva manera de dirigirse hacia las cosas que los recursos de la motivación sígnica le permitieron explicitar. Su actividad poética se originó, precisamente, como consecuencia del sentimiento de frustración que le había causado no poder verbalizar con rigor la realidad circundante, por lo que, en lugar de tratar de describir las cosas mediante las nociones que de ellas dispondríamos que siempre juzgaba falaces e inadecuadas-, resolvió definirlas en tanto que objetos de experiencia visual y marginando así lo concebible a fin de proyectar lo visible ${ }^{3}$.

Por consiguiente, Ponge optó por los objetos más comunes y elementales de la vida cotidiana calificando su poética de logoscopique (Ponge, 1971a: 177), es decir, como si de un instrumento para la visión se tratase (-scopio), porque consideraba, en definitiva, que aquello que quería representar "ce ne sont pas mes pensées, ma philosophie, ma théorie. [...] Ce sont mes façons de voir"”. Por lo tanto, y como señaló Lévy (1993: 85), era evidente que el proyecto pongeano no radicaba en "une herméneutique. Ponge n'est pas [...] à la recherche d'un sens caché derrière les objets. Son projet [...] est plutôt de rendre l'objet par la parole"; pero si su objetivo era el de "rendre présent, par le langage, un objet absent" (Lévy, ibid.), las expresiones descriptoras de sus textos tenían que ser el reflejo de los objetos por ellas designadas, por lo que su tarea se inscribiría en el ámbito de la palabra cratiliana en tanto que sólo un vínculo de semejanza entre el objeto y su apelativo podría explicitar dicha correlación.

A tenor de lo dicho, el planteamiento lingüístico de Ponge no podría sino basarse en el principio de la motivación, ya que para ilustrar un objeto mediante la palabra sería necesario que ésta trasluciese, de algún modo, las características perceptibles

\footnotetext{
${ }^{3}$ Esta época de incertidumbre y de búsqueda de nuevos modos de expresión más acordes con lo real se relacionaría también con ciertos episodios de bloqueo verbal que sufrió el poeta, como los que le impidieron, y por dos veces, acceder a los estudios superiores de filosofía al enmudecer en las pruebas orales. Esta crise logique, tal y como él la denominaría más tarde, puede rastrearse en algunos de los breves textos en prosa que Ponge intituló Proêmes (1948), como «Drame de l'expression»o «Des raisons d'écrire»; y particularmente, en las notas de su «Séconde méditation nocturne» (1943), unas notas que se incluyeron en uno de los volúmenes póstumos que editó J. Thibaudeau a partir de escritos de Ponge aún inéditos (Nouveau nouveau recueil, II). Por otra parte, cabe precisar que, tal y como le refirió Ponge a G. Sartoris en 1983, fue la lectura de Jacob Cow le pirate ou si les mots sont des signes (1921), de J. Paulhan -durante sus inicios, su único lector y crítico-, la que constituyó para él una auténtica revelación, puesto que esa lectura le hizo comprender hasta qué punto era necesario considerar la relatividad del lenguaje respecto de la realidad por él designada (Ponge, 2002: 1434-35).

${ }^{4}$ La cita se extrae de las notas de la «Seconde méditation nocturne» que mencionábamos en la nota anterior (Ponge, 2002: 1191). A propósito de la mirada pongeana, vid.: CORDERO CORTÉs, R. (2009): "Hacia una poética de la evidencia: Modalidades de la mirada en Le Parti pris des choses de Francis Ponge", Thélème. Revista Complutense de Estudios Franceses, no 24, 39-51. Asimismo, podríamos recordar que, de un modo metafórico, el poeta declaró que, para llevar a cabo su tarea, cabría recurrir a distintos instrumentos ópticos, es decir, "faire appel: [...] au télescope, au microscope, aux verres de presbyte et de myope" (Ponge, 1952: 46).
} 
de dicho objeto; y de ahí que Ponge se circunscribiera a la realidad de naturaleza visible, puesto que una entidad abstracta cuya estructura no fuera susceptible de ser visualmente percibida no podría luego ser descrita a través de una expresión que evidenciara los rasgos por los que la identificaríamos. Así pues, el poeta tuvo que esbozar un proyecto lingüístico en el que pudiera darse una relación directa y biunívoca entre las palabras y las cosas, por lo que, más que de una lengua como estructura, estaríamos hablando de una nomenclatura; de una cuyos nombres representaran las cosas de un modo fidedigno conforme a su naturaleza y con relación a su significación: luego el poeta tuvo que crear tanto neologismos para nombrar pertinentemente esos objetos de la realidad visible, como definiciones que se ajustaran a sus respectivos denominativos.

Conforme a lo expuesto, analizaremos aquí los procedimientos de los que se sirvió Ponge para desarrollar su actividad poética y que vertebrarían lo que denominó su méthode métalogique $e^{5}$; un método que supuso la asunción de un planteamiento lingüístico nomenclaturista que se fundaba en la tesis ontológica del cratilismo y que tendría por principio epistemológico el reconocimiento de las cosas por las palabras y viceversa: hecho que posibilitaría, en fin, que "ces choses nommées par Ponge une fois lues, nous n'entendons plus de simples noms, mais les noms des choses selon une relation réelle d'appartenance" (Sartoris, 1989: 77-78).

\section{Un método para una poética: la méthode métalogique y la parole à l'état naissant.}

El descrédito de las ideas condujo a Ponge a no querer someterse al yugo de ningún dogma ideológico ni al de ninguna corriente estética o estilística, pues para él era necesario que un poema fuese "seulement descriptif (sans intrusion de la terminologie scientifique ou philosophique)" (Ponge, 1967: 194); en consecuencia, más que de un principio teórico, resolvió que, para su poética, que no debía regirse ni por "une mystique" ni, todavía menos, por "une illusion", lo fundamental sería adoptar "une méthode" (Textes hors recueil, Ponge, 2002: 1391); un método de creación verbal que calificó de metalógico en tanto que le permitiría, yendo más allá de la (falsa) lógica de los sentidos convencionales, describir las cosas tal y como verdaderamente son para nuestra experiencia. Y todo ello al objeto de corregir la habitual "infidélité des moyens d'expression" (Ponge, 1967: 194), porque para Ponge, en efecto, entre el vehículo sígnico y la realidad extralingüística a la que éste se referiría - convencional y arbitrariamente, en términos saussureanos- se habría instaurado un desfase que sería necesario subsanar ${ }^{6}$.

\footnotetext{
${ }^{5}$ No se debería confundir la métalogique pongeana con el métalogisme del Grupo de Lieja (Grupo $\mu$ ), que sería el nombre con el que este círculo de investigadores se referiría a aquellas figuras -o métaboles- que modificarían el valor lógico de la frase (las que Fontanier designó como figuras de pensamiento). La operación metalógica de Ponge incluirá, como veremos, todo tipo de procedimientos; y como se deduce del término, habría implicado la superación de esa crise logique que mencionábamos en la nota $\mathrm{n}^{\circ} 3$.

${ }^{6}$ Por este motivo, Ponge ha sido juzgado como présaussurien por algún crítico. Veamos, por ejemplo, cómo lo argumentaba Giordan (1976: 490) a propósito de Le Parti pris: "Lire la signification
} 
Ciertamente, Ponge le declaró a Sollers (1970: 72) que la base de su método poético podría contener, en cierta manera, "l'irrationnel", pero esto no suponía que el poeta se adscribiese a las contingencias del automatismo surrealista tal y como en seguida precisó ${ }^{7}$, porque su irracionalidad debería entenderse en tanto que nunca quiso adoptar los significados consuetudinarios de las palabras al ser éstos los que nos habrían procurado, siempre según el poeta, las falsas nociones acerca de la realidad; y de ahí que afirmara necesitar desembarazarse de la tendencia de decir las cosas "plates et conventionnelles. Ce n'est vraiment pas la peine d'écrire si c'est pour cela" (Ponge, 1952: 89).

En consecuencia, el procedimiento metalógico pongeano debería conseguir que, dado un significante, su significado nos condujera hacia su objeto de forma motivada y anticonvencional; razón por la que ese ir 'más allá' de la lógica no supondría abrazar el dominio de lo comúnmente entendido como ilógico sino todo lo contrario, porque mediante su método, la entidad real debería verse reemplazada "par une formule logique (verbale) adéquate" (Ponge, 1971a: 26). Como apuntaba Braque (1952: 40), siempre una autoridad para Ponge ${ }^{8}$, la lógica, en definitiva, no sería sino "un effet de perspective", y ya sabemos que la mirada poética pongeana (sus façons de voir) lo que perseguía era romper con la visión tradicional tal y como lo había hecho la pintura con respecto al espurio punto de fuga de la perspectiva renacentista. Así pues, el vocablo logique en el ideario de Ponge no apuntaría sino al ámbito de lo que para él significaba la juste parole, así que la métalogique activaría todos los procedimientos a través de los que el autor trataría de cumplir su

dans le rapport au référent, c'est nier implicitement qu'un mot est une valeur dans un contexte langagier (et non en soi), dans une chaîne signifiante linéaire et dans le non linéaire". De hecho, Ponge conocía bien los trabajos de Saussure tal y como se demuestra en la entrevista que concedió a A. Rudolf el 4 de mayo de 1971 («Francis Ponge: An interview», Modern Poetry in Translation, $\mathrm{n}^{\circ}$ 21, 1974, 16-18), pero como anotábamos en la primera sección, lo que hacen los poetas no es describir el funcionamiento del sistema de la lengua, sino desarrollar la creatividad del verbo a partir del pensamiento imaginativo.

${ }^{7}$ Ponge apostilló de inmediato que nunca podría practicar la "écriture automatique" (Sollers, 1970: 72), pues la distancia ética y estética entre Ponge y el grupo de Breton siempre fue notoria pese a ciertas concomitancias que podríamos calificar de coyunturales. Es cierto que Ponge publicó uno de sus textos en el primer número de Le Surréalisme au service de la révolution (1930), y que llegó a firmar el segundo manifiesto surrealista y a frecuentar tanto el $\mathrm{n}^{\circ} 42$ de la calle Fontaine (chez Breton) como el famoso café Cyrano; pero muy pronto se distanció del grupo por falta de sintonía con el credo surrealista: "dès la jeunesse enfin, j'ai été intéressé par les problèmes que posait le surréalisme... C'étaient les mêmes que je posais. Pourquoi écrivez-vous?, À qui est-ce que je parle? [...] Tout ça me préoccupait beaucoup. Et puis aussi le fait qu'il était une réaction contre le langage académique. [...] Mais le côté théâtral de l'activité surréaliste m'ennuyait, ne correspondait pas à mon tempérament. Et puis, je ne suis pas un homme de groupe" (Pop, 1988: 15). En realidad, y tal y como precisó Gleize (1988: 57), Ponge, “Avant de s'opposer au surréalisme, c'est des surréalistes qu'il se différencie".

${ }^{8}$ Ponge conoció a Braque por mediación de Paulhan en 1945, y en seguida se estableció entre ellos un estrecho lazo en tanto que los unía un ideario común, pues el lema braquiano "Le tableau est fini quand il a effacé l'idée" (Braque, 1952: 27) podría asimilarse al de Ponge: "Le poète ne doit jamais proposer une pensée mais un objet" (Ponge, 1967: 130). Fueron muchos los textos que Ponge escribió a propósito de Braque; y a su vez, el pintor ilustró algunos de los textos del poeta y diseñó la cubiertas de la primera edición de Proêmes (1948) y de Le Peintre à l'étude (1948), ambos editados por la NRF. 
objetivo: el de crear unas nociones inéditas de las cosas con el fin de que éstas nos representaran genuinamente los referentes de la realidad, o bien el de acuñar nuevas denominaciones para que nos revelasen esa relación de semejanza que debería vincular un objeto a su apelativo.

Por consiguiente, y con la finalidad de alejarse de "toutes les règles existantes" (Ponge, 1952: 132), el poeta juzgó imprescindible regresar a un utópico estado originario: a aquel en el que, por vez primera, el hombre tuvo la necesidad de dar nombre a las cosas, pues mediante ese nuevo nombrar, Ponge podría refundar el mundo al constituirse, el acto de la denominación, en un acto de creación: "Nommer, c'est créer: une chose qui n'a pas de nom existe-t-elle? Inversement, donner un nom, c'est faire surgir à l'existence" (Valette, 1988: 27). Y así lo argumentó el poeta en diferentes entrevistas:

les mots que nous employons [...] sont les choses premières. Quand on dit: "Au commencement était le Verbe", eh bien, je pense que c'est ça que ça veut dire. Quand le premier homme parlant a désigné ça, il a percé sur ce chaos absolument sans forme, il a placé une grille, la grille du langage. $\mathrm{Il}$ a décrypté ce chaos et il a fait [...] ce monde. [...] C'est-à-dire que, à mon sens, le poète, qui est tout sensible au monde extérieur, est, comment dirais-je? Dans l'état, presque, du premier homme. C'est-à-dire que les mots, tels qu'ils sont employés actuellement ne lui suffisent pas et il essaye [...] de s'exprimer autrement que par les mots usés, fatigués, qui n'ont plus de rapport avec leur origine (Pop, 1988: 12).

Je pense que toutes les choses qui ne sont pas loin, sinon de l'onomatopée, du moins de la première prononciation articulée du langage humain [...] nous ramènent au plus près de la naissance, non seulement de la parole, mais du monde lui-même [...]. C'est justement en distinguant les objets du monde extérieur et en les nommant, qu'on les crée dans une certaine façon; sinon ils ne dureraient que dans la forme de chaos. C'est en les nommant qu'on crée le monde, en posant la grille du langage (Dahlin, 1980: 276).

Todas estas ideas convergerán en lo que Ponge denominó el état naissant de la parole, es decir, el estado imaginario al que deseaba circunscribir su lenguaje, y que se correspondería con ese momento inaugural en el que las palabras se habrían originado para dar nombre a las cosas relacionándose íntimamente con ellas ${ }^{9}$. Y tal y como lo precisó el poeta en el Colloque de Cerisy, ese momento de cristalización lingüística también coincidiría con el del mismo descubrimiento de la realidad por parte del hombre:

il s'agit du surgissement à la fois des choses et de la parole; du moment où la nécessité de désigner, c'est-à-dire de distinguer du chaos une chose, et, en même temps, d'exprimer un sentiment [...]. Alors, en présence d'une chose qui apparaît, qui vous apparaît parce que vous la distinguez dans le chaos, vous exprimer le sentiment violent qui vous oblige à parler, [...] vous nommez la chose. [...] Ce même mot [...] c'est une nomination, c'est une désignation, une

\footnotetext{
${ }^{9}$ No obstante, no tendría nada que ver este nombrar pongeano con el de Eternidades (1916-1917) de Juan Ramón Jiménez, por ejemplo, puesto que los nombres exactos que éste quería dar a las cosas por la inteligencia creadora deberían revelar su esencia más allá de su presencia empírica; y una esencia que ligaría con una infinitud con la que también Jiménez desearía, progresivamente, diluir expresión y pensamiento. Con todo, lo determinante es señalar aquí que, aun de dispar modo, para los poetas la palabra es fundacional y, la denominación, creadora.
} 
distinction de l'objet; vous apposez sur le chaos la grille du langage, de votre langage, et en même temps vous communiquez cela (Bonnefis/Oster, 1977: 36).

A propósito de este nombrar fundacional podríamos retrotraernos, pues, al contexto del Crátilo platónico: Hermógenes, como sabemos, defendía la tesis convencionalista al secundar la imposición de las denominaciones por pacto o consenso; y Crátilo, en cambio, apoyaba la tesis naturalista al sostener el argumento de la innata justedad de los nombres, que responderían a la existencia de un vínculo natural que los asociaría a los objetos por ellos designados, porque si la naturaleza de un objeto determinaba la forma ideal de su nombre como instrumento que habría de servir para designarlo, el acto de nombrar consistiría en imprimir esta forma idónea a la materia lingüística (a los sonidos y a las sílabas, tal y como se precisa en el Crátilo: $389 \mathrm{~d}-\mathrm{e} ; 390 \mathrm{e} ;$ y $423 \mathrm{e})^{10}$. Y de ahí que calificásemos a Ponge de poeta cratilista, dado que, para él, se deberían reconocer las cosas comme semblables à leur nom (Ponge, 1971b: 22).

En la obra de Ponge, pues, "l'objet choisi est confronté à l'arbitraire du signe qui le nomme, et le poème s'efforce de corriger cet arbitraire par diverses manipulations" (Luebbers, 2007: 860), porque sería precisamente a través del poema -y por medio de los diferentes recursos de la técnica metalógica- que Ponge trataría de corregir esos desajustes entre un objeto y su denominativo. Además, si, como anotó Genette, uno de los "terrains favoris" de la dialéctica socraticoplatónica era el de la "fabrication artisanale"11, veremos que Ponge mencionará a menudo ese proceder de la fabricación; y no sólo con relación al hecho de crear denominativos, sino por la misma naturaleza de su quehacer poético, pues afirmaba preferir "un objet fait de l'homme (le poème, la création métalogique), qu'un objet sans mérite de la Nature" (Ponge, 1967: 193-194).

Así pues, y como señaló Lévy (1999: 13), en Ponge "Il ne s'agit pas en effet d'imiter le monde ou de le montrer [...] mais de le refaire -littéralement- en paroles", por lo que la métalogique se convertiría, como anotó Farasse (1996: 18), en "une méthode pour faire passer les mots de l'autre côté, celui des choses". El

${ }^{10}$ El Crátilo de Platón refleja el verdadero debate physis/thésis que se dio en la antigua Grecia, aunque cabe apuntar que la polémica no se originó en el ámbito lingüístico, sino en el de las leyes: si éstas competían al arbitrio humano, o bien al divino. Asimismo, y relacionado con este debate, encontraríamos la intensa polémica que enfrentó a los que defendían la regularidad o analogía del lenguaje (escuela de Alejandría) con los que sostenían su irregularidad o anomalía (escuela de Pérgamo), siendo los primeros los partidarios de la tesis naturalista, y los segundos, de la convencionalista. En cuanto a esta querella, fue pródigamente referida por Varrón en De lingua latina, aunque mediante un razonamiento en círculo, el autor no tomó partido por ninguna de las dos posiciones. Lo que nos interesa aquí, pero, es que, en cierto modo, algunas de las deducciones etimológicas que estableció Varrón en su De lingua latina podrían asemejarse a las de Ponge, porque a Varrón le importaba más revelar la sociedad romana de su tiempo a través de la palabra, que los orígenes de la palabra misma.

${ }^{11}$ Así precisaba Genette (1976: 14) la secuencia argumentativa: "nommer, c'est fabriquer un nom, le nom est un instrument de la relation entre l'homme et la chose, nommer est donc fabriquer un instrument". 
poeta, en suma, se habría propuesto hacer del mot la chose o, más propiamente, "transformer la parole qui nomme la chose en la chose nommée" (Lévy, 1999: 12):

Seule la littérature (et seule dans la littérature celle de description -par opposition à celle d'explication-: parti pris des choses, dictionnaire phénoménologique, cosmogonie) permet de jouer le grand jeu: de refaire le monde, à tous les sens du mot refaire [...]. A la vérité, expression est plus que connaissance [...]: c'est refaire. (Ponge, 1967: 200).

Para Ponge, de hecho, las civilizaciones primeras sí habrían sido conscientes de esa recíproca correspondencia entre las palabras y las cosas, lo que permitía que una comunidad lingüística pudiera tener la certeza de expresarse con total justedad ${ }^{12}$; pero el hombre moderno habría perdido esa aptitud:

Dans les civilisations anciennes il était clair que les mots et les choses étaient absolument identiques [...]. Il y avait vraiment correspondance entre les sensations et le langage. Il est évident que nous sommes loin de là. La plupart des gens ont perdu ce sentiment, cette espèce d'instinct à la fois naïf, enfantin, et sage (Dahlin, 1980: 281).

Por lo tanto, si bien el primer apelativo atribuido a un objeto habría sido efectivamente impuesto por una razón de natural semejanza, hoy habríamos perdido la capacidad de percibir ese vínculo al aprehender el objeto de un modo erróneo a partir de la noción convencionalizada que a él nos remitiría; así que para rectificar la inadecuación que se habría instaurado entre signans y signatum sería necesario, además de observar nuevamente dicho objeto, hacerlo atendiendo a su nombre con la intención de restituirlo

à sa signification première (ou complète), afin de le rapprocher à nouveau de la chose, conçue dans son épaisseur et sa différence véritables: celles qui la caractérisaient quand elle fut nommée pour la première fois, celles qui provoquèrent le besoin, le désir de la nommer. (Ponge, 1971b: 22-23).

En consecuencia, toda la poesía de Ponge se verá condicionada por esta concepción no sólo ostensiva del lenguaje, sino incluso sustitutiva, puesto que su planteamiento de hacer retroceder las palabras hasta un utópico état naissant acabaría por implicar que, más allá de considerarlas como los indicios de las cosas, las entendiera ya como las cosas mismas: "les mots, déjà, sont autant choses que

${ }^{12}$ Con todo, más que de una correspondencia entre las palabras y las cosas, se trataba de una relación de causalidad fundamentada en una especie de contigüidad natural, ya que para el hombre primitivo -en su sentido etimológico de 'primero'- la actividad lingüística no sería, como anotó Kristeva en "Anthropologie et linguistique" (1969), un "acte d'idéalisation ou d'abstraction, mais [...] une participation à l'univers environnant", porque el lenguaje, antes de concebirse como un ailleurs mental, se entendía "comme un élément cosmique du corps et de la nature [...]. Son lien avec la réalité corporelle et naturelle n'est pas abstrait ou conventionnel, mais réel et naturel. L'homme primitif ne conçoit pas de dichotomie entre matière et esprit, réel et langage, et par conséquent entre référent et signe, et encore moins entre signifiant et signifié: pour lui, ils participent tous au même titre d'un monde" (Kristeva, 1981: 56). Así pues, para muchas comunidades tribales, el nombre de alguien era tan importante como cualquiera de las partes de su cuerpo, siendo equiparable, por ejemplo, a los ojos o a los cabellos. Y mofarse de un nombre suponía, consecuentemente, infligir "une blessure physique" (ibid., 57). 
mots" (Ponge, 1971b : 23). Y así, la actividad poética de Ponge consistirá también en la de recrear un nuevo fundamento lingüístico que pudiera justificar esa correspondencia entre lo real y lo nombrado, porque sería entonces necesario concebir un lenguaje-nomenclatura a fin de que el universo visible pudiera ser descrito mediante un vocabulario; y uno cuyas palabras que lo constituyeran ocuparan el lugar de las cosas como si la función más importante del signo fuera, propiamente, la de la suppositio; tal y como lo había formulado, por ejemplo, el nominalista Ockham: "Verbum supponit pro re: le mot suppose pour la chose" (Maldiney, 1993: 159). Veámoslo a continuación.

\section{El fundamento lingüístico de la poética pongeana: la lengua como nomenclatura.}

Wittgenstein, al inicio de sus Investigaciones Filosóficas (1953) -aunque lo había referido ya al comienzo de su Cuaderno marrón en 1934-, hablaba de una rudimentaria teoría del lenguaje que identificaba con la que se deducía de un párrafo de las Confesiones ( $\mathrm{I}, 8)$ en donde san Agustín explicaba cómo de niño habría aprendido a hablar viendo cómo los adultos se dirigían a los objetos que nombraban, y deduciendo así de qué cosas serían signo las palabras que reemplazaban a tales objetos; una práctica que, a todas luces, sólo resultaría efectiva en caso de que el niño supiera ya una lengua e ignorase la que, mediante los gestos de los adultos, estaría entonces aprendiendo, dado que lo pertinente no es a qué objetos se dirigen las palabras, sino cómo funciona el sistema lingüístico ${ }^{13}$. De no ser así, estaríamos hablando de un lenguaje que no haría distinción ninguna entre los diversos tipos de signos y mediante el cual a cada palabra le correspondería, inequívocamente, un objeto, como si el acto de denominar fuese equivalente al de colocarle a cada cosa un rótulo; y huelga decir que de nada serviría ese procedimento de etiquetaje desconociendo la instrucción por la que funciona la etiqueta, porque, como señalaba Wittgenstein (1988: 59), no puede confundirse el significado de un nombre con el portador del mismo.

En la obra de Ponge, no obstante, esa elemental correspondencia cobraría sentido, dado que, como precisó el poeta en Cerisy, en ese imaginario état naissant al que deseaba retrotraer su lenguaje las palabras no dispondrían aún de significado, puesto que únicamente habrían sido articuladas con el fin de distinguir y dar nombre a las cosas:

Justement, le langage à l'état naissant supprime les significations. Le propre du poète c'est justement de se replacer au moment ou les significations ne sont pas des significations, où il parle

\footnotetext{
${ }^{13}$ No obstante, cabe precisar que la concepción del lenguaje de san Agustín no era tan restringida: en De Doctrina christiana (II, I, 1), por ejemplo, definía el signo como esa entidad a partir de la que, más allá de la impresión que causa, provoca en la mente una cosa distinta ("Signum est enim res praeter speciem, quam ingerit sensibus, aliud aliquid ex se faciens in cogitationem uenire"); es decir, que no le presuponía al signo una elemental función sustitutiva, sino una preeminentemente intelectiva. $\mathrm{Y}$ ese mentalismo sería luego retomado, y elevado a la máxima potencia, por la Grammaire y la Logique de Port-Royal.
} 
à nouveau, il cherche à parler à nouveau, comme a parlé le premier homme, c'est-à-dire qu'il se trompe de mot, parce que les mots du langage courant, avec leurs significations figées, ne lui sont pas convenables, justement. (Bonnefis/Oster, 1977: 38).

Las palabras de Ponge, en efecto, más que simbolizar o significar, evidenciarían sus respectivos elementos de designación a partir "d'une sorte de redondance du signe par rapport à l'objet: entre eux pas d'espace de signification, rien qu'un rapport de désignation. Le mot colle à la chose exactement comme si on l'écrivait sur elle" (Farasse, 1977: 206-207). Así pues, comprenderíamos que Ponge se declarara también seguidor de Lucrecio -y cabe aquí recordar que una de las aspiraciones del joven Ponge había sido la de "écrire une sorte de De natura rerum" (Ponge, 1967: 177)-, pues la sentencia lucreciana más característica, utilitas expressit nomina rerum, revelaría perfectamente el sentido de esa necesidad del hombre del nombrar primigenio a la vez que justificaría que la función primera del lenguaje habría sido la de "donner des noms aux choses, c'est-à-dire créer un vocabulaire" (Malmberg, 1977: 430). Y acudiendo al Libro V del De natura rerum, confirmaríamos no sólo la vinculación de Lucrecio a la tesis naturalista, sino incluso la coincidencia de que también el poeta latino adujera como argumento la forma en que los niños aprenden a hablar mediante definiciones ostensivas, es decir, lo mismo que había referido san Agustín y comentado Wittgenstein:

Pero los variados sonidos de la lengua, la Naturaleza impulsó al hombre a emitirlos, y la necesidad formó los nombres de las cosas, por un instinto no muy diferente al que vemos que induce al niño, incapaz de hablar, a servirse del gesto y señalar con el dedo los objetos presentes (Lucrecio, 1983: 1030).

Y de ahí que las características de la obra pongeana llevaran a Calvino a reconocer a Ponge como "il Lucrezio del nostro tempo, che ricostruisce la fisicità del mondo attraverso l'impalpabile pulviscolo delle parole" (Calvino, 1993: 84). Por lo tanto, Ponge no podía concebir el significado de las palabras como una abstracción, sino como "le rapport aux choses du monde extérieur, et son évocation précise" (Ponge, 1965: 137); circunstancia que también justificaría que a lo largo de toda su producción prevaleciera el sustantivo, dado que el nominalismo favorecería la articulación de ese lenguaje-nomenclatura cratilista a través del que podría llevarse a cabo, y con mayor eficacia, la descripción de una realidad objetual y empírica que sería la que se habría constituido como el universo de referencia del poeta.

Ya en el Sofista platónico, los sustantivos aparecen como los elementos designadores de objetos por excelencia, mientras que los adjetivos y verbos designarían, respectivamente, cualidades -0 propiedades- $\mathrm{y}$ acciones $-\mathrm{o}$ procesos ${ }^{14}$. Como señaló Kleiber, la tesis del predominio designador de los nombres sustantivos (o de los sintagmas nominales) se explicaría, por un lado, por el hecho de creer que los seres y las cosas, en tanto que entidades "auxquelles renvoient les noms, ont une

\footnotetext{
14 “Ce qui exprime les actions, nous l'appelons verbe [...]. Quant aux sujets qui font ces actions, le signe vocal qui s'y applique est un nom" (Platon, Le Sophiste; en Rey, 1973: 16).
} 
existence plus réelle que les qualités, propriétés et actions, entités auxquelles renvoient (ou qu'expriment,-et ce changement de verbe est révélateur-) les adjectifs et les verbes" (Kleiber, 1981: 35); y por otro, porque, generalmente, "les qualités et propriétés, actions et procès exprimés par les adjectifs et les verbes se rapportent aux êtres ou choses nommés par les noms: ils sont dits des objets désignés par les noms" (ibid.). No obstante, Kleiber señala que esta preponderancia del nombre es, en verdad, relativa, puesto que el sustantivo no es una categoría gramatical universalmente homogénea ${ }^{15}$; pero el método poético de Ponge, que reclamaba, como habíamos apuntado, una elemental correspondencia entre las palabras y las cosas, también presupondría una proporcional elementalidad en lo que se refiere al fundamento lingüístico, y de ahí el carácter de nomenclatura que Ponge atribuía a la lengua.

Así pues, formará parte de la métalogique pongeana el analizar y desglosar hasta los nombres propios tal y como sucedía en el Crátilo, pues cabe recordar que en el Diálogo platónico la discusión se iniciaba a propósito del apelativo Hermógenes, del nombre del interlocutor que defendía la tesis convencionalista, pues al ser éste hijo de Hipónico, alegaba, contra la tesis naturalista, que su nombre se contradecía con la realidad (Hermógenes: 'engendrado por Hermes'). Pero como en Ponge se impondría siempre la autoridad cratiliana, los nombres analizados por el poeta resultaban siempre los legítimos receptáculos de los rasgos atribuibles a sus portadores, motivo por el que, en muchos de sus textos, los nombres propios eran citados, precisamente, por la información denotativa que podrían revelar:

les noms [...] peuvent être considérés comme j'ai dit des "socles d'attributs", c'est-à-dire qu'ils remplacent un grand nombre d'adjectifs ou d'attributs, vous comprenez, de qualités si vous voulez [...].C'est pour ça que souvent des noms propres purement et simplement apparaissent dans mes œuvres, pour remplacer un développement de qualités (Ponge, 2002: 1421; fragmento de una entrevista concedida a F. Chevrier, F. Berthet y J. Thibaudeau, en 1976).

Los juegos onomásticos serán, en efecto, muy frecuentes en la obra de Ponge (y más los relativos a la antroponimia que a la toponimia); y así, a propósito del nombre Claudel, por ejemplo - poeta al que tanto admiraba precisamente por su preocupación por el lenguaje y por su atención a la etimología (Spada, 1988: 31) ${ }^{16}{ }^{-}$,

${ }^{15}$ En la lengua china, por ejemplo, todas las palabras son susceptibles de ser nombres o verbos (Kleiber, 1981: 36), y ya Benveniste (1966: 152) había apuntado que "Une opposition entre procès et objet ne peut avoir en linguistique validité universelle, ni critère constant", pues como él mismo argumentaba mediante ejemplos de lenguas amerindias, algunas formas verbales se emplean como nombres e, inversamente, algunas nominales se conjugan como verbos.

${ }^{16}$ Ponge siempre afirmó que admiraba "profondément l'œuvre poétique de Claudel" (Sollers, 1970: 34), y que apreciaba especialmente los breves textos en prosa de Connaissance de l'Est. Además, sería necesario no olvidar que Claudel fue también cratiliano, pues en «La poésie est un art» (1952), declaró lo siguiente: "Entre un objet quelconque, entre un quelconque fait, sentiment ou action, et sa représentation sonore ou graphique, il n'y a pas apparemment de rapports (quoique personnellement avec Platon je sois persuadé du contraire" (Claudel, 1965: 52). En sus Idéogrammes occidentaux (1926), más bien pictogramas, ensayó la motivación entre la forma de la escritura y el sentido de las expresiones escritas; y al igual que Ponge, dio mucha importancia a la nomination, tal y como lo certifica su Art poétique (1904): "le nom est une formule conjuratoire dont nous nous servons 
Ponge apuntó que "c'est entre clame et claudique" (Ponge, 1999: 460) por el temperamento que le atribuía al individuo. Y a lo largo de Pour un Malherbe, no dejaba de mencionar la mauvaise herbe con la que se identificaría el nombre del poeta de Caen, pero porque Malherbe, que era otro de sus autores señeros, supo destacar en condiciones desfavorables -frente a la popularidad de los poetas de la Pléiade - al igual que la hierba silvestre logra atravesar pavimentos y empedrados. Además, esta imagen sintonizaba con la de la densidad pétrea y arquitectónica con la que asociaba el estilo de Malherbe, pues juzgaba que su elocución era "comme les murailles de Chaldée ou d'Égypte. Poésie de pierre grise et abrupte" (Ponge, 1965: 178).

Asimismo, Ponge contaba con que, con mucha pertinencia, un nombre de pila podría hacer las veces de adjetivo atributo del apellido al que acompaña; y así lo ilustró con el antropónimo Denis Roche, el nombre de uno de los pocos poetas de su tiempo que apreció:

Il me semble parfois que le prénom d'une personne est un qualificatif (un adjectif, une épithète) par rapport au nom (patronyme) qui serait, lui, substantif. Une roche, une roche, un rocher, peut-il être dionysiaque? Eh bien, en voici la preuve. Le qualificatif de son prénom (dionysiaque) précédant le substantif Roche voilà ce qui m'est sensible [...] quand j'envisage sérieusement en moi la notion "Denis Roche" (Ponge, 2002: 1716; fragmento de un manuscrito de 1974).

Por otra parte, buscaba para sus descripciones palabras cuya presencia estaría justificada por las características que atribuía a ciertos nombres propios, o bien creaba neologismos derivados de éstos en función de las mencionadas características $^{17}$; y en ocasiones, la presencia de un determinado nombre provocaba que a lo largo del poema apareciesen voces que contenían los fonemas de los que se componía ese nombre en cuestión, como en el caso del texto dedicado al artista Gérard Vulliamy. Así pues, el mencionado texto -que Ponge tituló, elocuentemente, "Prose sur le nom de Vulliamy"-, aparecerá repleto de expresiones que contienen la

pour provoquer un certain état de notre tension personnelle, correspondant à tel objet extérieur, et qui désormais pourra lui servir d'image, de mise en marche, de clef' (Claudel, 1967: 181).

${ }^{17}$ Un caso ejemplar lo encontramos en Pochades en prose, especie de carnet de voyage escrito entre 1947 y 1948. En ese texto, Ponge habla del color del paisaje de Argelia, que sería de un rosa "à vrai dire assez sacripant" (Ponge, 1971a: 80); y en una conferencia que dictó en la Technische Hochschule de Stuttgart en 1956, el poeta explicaría la razones de la elección de ese adjetivo: "J'étais en Algérie, dans une maison adossée aux premiers contreforts de l'Atlas, d'où l'on voyait trente kilomètres de plaine et la ligne des collines qui bordent la mer, le Sahel, et cette chaîne de petites collines avait une couleur dont je voulais trouver l'adjectif, le mot. [...] Finalement j'ai trouvé un mot, il existe, je ne l'ai pas inventé [...]. Sacripant. Le mot me plaît. Rose sacripant. Ça y est. J'étais sûr que je l'avais. Ça y était. Je suis allé au dictionnaire après. [...] Sacripant: de Sacripante, personnage de l'Arioste, tout comme Rodomonte. Rodomonte, qui signifie rouge montagne et qui était Roi d'Alger. Voilà la preuve. Quand on a ça, on est sûr. C'est une chose qui n'arrive pas toujours, mais je veux dire que le sentiment d'avoir le mot était justifié" (Ponge, 1971a: 288-289). Asimismo, podríamos apuntar que el término también suponía una deuda proustiana, porque la palabra sacripant nos remite a Miss Sacripant, que fue el apelativo que le dio el pintor Elstir de $\grave{A}$ la recherche al retrato travestido de Odette de Crécy. Para un estudio detallado sobre la cuestión, remitimos a: VECK, B. (1992): "Flagrant délit de création. Rose, sacripant, Ponge et Proust”, Europe, nº 755, 113-119. 
fricativa sonora y la líquida palatal, puesto que éstas serían las consonantes más destacadas del apellido del artista: "Vulliamy veuille", "l'œil du mille", "jungle en famille", "volubilité alliée", "Violence et vaillance", "vulliance", "vulliamment", etc. (Ponge, 1999: 142) ${ }^{18}$.

Ciertamente, autores contemporáneos de Ponge habían atendido también a las posibilidades expresivas de la onomástica, y podríamos recordar aquí el texto lúdico a propósito de los "Noms propres" que incorporó Queneau a sus Exercices de style. De hecho, y al margen de toda la simbología relativa a los nombres que podríamos hallar en la literatura universal, precisamente en la literatura francesa se habían dado ya ejemplos paradigmáticos de estos juegos con la antroponimia gracias a Rabelais, Molière o Jarry ${ }^{19}$. A excepción de Queneau, a quien no citó nunca, Ponge sí había hecho mención de estos otros autores, aunque puntualmente y no con relación a esta circunstancia, puesto que su interés por los nombres se debía, pese al carácter lúdico que entrañaba dar pertinencia semántica a ciertos elementos a priori no significativos, al proceder cratiliano que animaba toda su obra. Pero si bien en el caso de los nombres propios el hecho de atribuirles significados revestiría pocas dificultades en tanto que las características que les asignaba el poeta se deducían presumiblemente- de la idiosincrasia de quienes los llevaban (y luego ya Ponge disponía que esos atributos pudieran inferirse de los rasgos fonéticos del nombre en cuestión), el problema surgiría con los nombres comunes. A diferencia de los propios, y en tanto que convencionalmente indicadores de una clase de denotados, los nombre comunes reclamarían, para su descripción, recurrir a un concepto, y de ahí la intrincada tarea de Ponge de crear nociones motivadas.

Así pues, y a partir del nombre de un objeto, el poeta advertiría, por una parte, el posible desfase que se habría instaurado entre éste y la realidad empírica designada; y por otra, el que se habría establecido entre éste y la noción con la que lo asociaríamos; coyuntura que habría de implicar, en fin, la doble dirección del método metalógico: parti pris des choses/compte tenu des mots. Veámoslo.

\section{Sobre la doble direccionalidad de la noción motivada (conceptacle). Ejemplos metalógicos.}

Como habíamos anotado, descubrir la falta de parentesco entre un objeto y su denominación era, en la mayoría de los casos, el punto de partida de la poética pongeana:

Découvrir [les choses] comme différentes de leur nom [est] ce qui nous fait, par conséquent, désirer les nommer mieux [...]. Ce qui nous fait reconnaître une chose comme chose, c'est

${ }^{18}$ El texto figura en Le Peintre à l'étude (1948), libro con el que Ponge empezó a escribir sobre arte y artistas, pues tal y como se lo refirió a J. Chevrier en 1976, también el mundo del arte concerniría a su parti pris: "Il n'y a pas de différence entre les textes sur les choses et les textes sur les œuvres d'hommes ou d'artistes" (Ponge, 2002: XIII).

19 Vid., por ejemplo, el estudio de M. R Ozaeta Gálvez centrado en ejemplos de la literatura francesa: "Los antropónimos: nociones teóricas y modalidades de transferencia", EPOS: Revista de Filología, n 18, 2002, 233-255. 
exactement le sentiment qu'elle est différente de son nom, du mot qui la désigne, du mot qui porte son nom, du mot dont elle est bien touchante de consentir à porter le nom. (Ponge, 1971b: 22-24).

Pero la cuestión es que no se trataría siempre, o no únicamente, de nommer mieux las cosas proponiendo un nuevo apelativo o bien modificando el habitual, porque advertir la impropiedad de un denominativo a menudo implicaba que Ponge descubriera la inadecuación del concepto comúnmente asociado a ese objeto en cuestión. Y es que, tras perderse el vínculo de semejanza originario entre las cosas y sus nombres, también las nociones mediante las que deberíamos reconocerlas habrían ido deteriorándose, puesto que habrían ido distanciándose de forma progresiva de la realidad que auténticamente experimentamos:

Autrement dit: si nous aimons les choses, c'est que nous les re-connaissons, je veux dire que nous les ressentons à la fois comme semblables à ce que notre mémoire avait conservé d'elles [...] et comme différentes de cette notion simplifiée et utilitaire (représentée par leur nom, le mot qui les désigne) (Ponge, 1971b: 23).

Pero si el quehacer poético de Ponge estribaba, como él mismo había detallado, en elaborar descripciones-definiciones de cosas (Ponge, 1971a: 18), el poeta no podía dejar de atender a las nociones relativas a esos objetos $-\mathrm{y}$, especialmente, a las que juzgaba espurias; y es por esto por lo que otra de las tareas de la métalogique será la de corregir esas nociones falaces relativas a las cosas para que también ellas nos condujesen hacia sus respectivos objetos de una manera naturalmente apropiada. En lo concerniente a los conceptos, pero, hablar de motivación no implicaría sino hablar de una teoría semántica acotada como referencialismo: la que postularía una identificación entre significar y referir.

En el ámbito de la filosofía del lenguaje, los denominados referencialistas eran los que, como en el caso de Russell, identificaban, en efecto, el significado con el referente, es decir, los que consideraban que el significado de una expresión sería la entidad real referida, y siendo entonces el acto de referir -o el de denominar, o el de estar por la cosa nombrada- la única función semántica. Así pues, el planteamiento de Ponge coincidiría con estos supuestos, dado que el poeta afirmaba que el lenguaje "n'a qu'une fonction, une seule fonction: celle de nommer, ou plus exactement, comme le dit admirablement la langue française, celle d'appeler" (Viñas del Palacio, 2003: 128). De hecho, Ponge conocía algunos de los trabajos de Russell, y como ya habíamos señalado, el poeta declaró en Cerisy que entendía la désignation como signification ${ }^{20}$; por consiguiente, las nuevas nociones que

${ }^{20}$ Sabemos, a partir de una entrevista que le concedió a S. Gavronsky en 1972, que Ponge apreciaba la lógica de Russell: "je préférais de très loin, d'une part Sénèque ou Épicure... un matérialisme teinté de stoïcisme, et par ailleurs, les logiciens anglais, comme les logiciens du XVIII ${ }^{\mathrm{e}}$ siècle... Locke... aussi du point de vue de la logique... Russell. J'ai commencé à aimer Russell et Comte" (Ponge, 2002: 1412); y como se extrae de un texto de 1924 que compiló Thibaudeau en el Nouveau nouveau recueil, I, el poeta elogiaba especialmente "La Logique de Leibniz par Russell" (Ponge, 2002: 1063), aunque, de hecho, La logique de Leibniz d'après des documents inédits es una obra de Louis Couturat que se publicó en París en 1901; lo que sucede es que este libro fue objeto de 
resolvió elaborar en nada se asemejarían a los habituales conceptos abstractos que asociamos a las cosas, porque debían constituirse como la expresión de la transitoria impresión fenoménica que habría sido causada por la percepción real de un objeto: por la proyección inmediata de la aprehensión factual del mismo. Una noción convencional, precisamente por el hecho de ser estable, ya sería, para Ponge, falaz e incompleta, puesto que ningún objeto podría ser descrito, en tanto que fenómeno, de una forma definitiva; y si la noción había de fundamentarse en lo verdaderamente experimentado con relación a su objeto, habría de ser tan fluctuante como él.

En consecuencia, Ponge decidió crear unos nuevos conceptos que se adecuasen a las cosas en virtud de las impresiones por ellas suscitadas y que habrían de relacionarse, como sabemos, con el mismo nombre de la chose en tanto que éste tendría que haber sido asignado en función de una justa y natural semejanza con la cosa misma. Pero la cuestión es que estas impresiones factuales de las que hablaba Ponge entrañarían, inevitablemente, recuerdos y emociones que el propio hablante habría interiorizado a propósito de cada una de las cosas experimentadas, por lo que el poeta aceptaba que esas impresiones no podrían ser sino subjetivas y arbitrarias (Bonnefis/Oster, 1977: 409). Ahora bien: precisamente esta subjetividad de la que se impregnaría el nuevo concepto sería, para Ponge, la huella más real y fidedigna del objeto en cuestión, así que consideraba que sus definiciones serían mucho más legítimas y dignas de crédito que las convencionales. Tratando de sustituir las habituales nociones que asociamos a las cosas por sus nociones poéticas, pues, Ponge transferiría, a los conceptos abstractos, la facticidad de las percepciones accidentales y de las emociones subjetivas; y de ahí que el poeta adoptara, para sus nuevas definiciones, el término conceptacle, puesto que éstas serían como receptáculos en los que habrían de incluirse todo tipo de impresiones y experiencias $^{21}$.

Como apunta el diccionario Littré -el instrumento fundamental de la poética pongeana junto con el alfabeto, tal y como lo declaró el mismo Ponge (Sollers, 1970: 72)-, el conceptacle es un "Terme de botanique" cuyo origen latino se remonta a "conceptaculum, réservoir, supin de concipere, recueillir". Por lo tanto, todas las resonancias semánticas de este término describirían muy elocuentemente las características del quehacer poético pongeano, dado que, como precisó Beugnot, el mencionado conceptacle,

derivé du mot concept et enrichi d'une désinence qui évoque le regard (spectacle) et le dépôt ou l'abri (habitacle, réceptacle), il rend fort bien compte des caractères multiples du poème chez Francis Ponge: saisie de l'objet à la fois comme réalité visible, sensible, concrète, comme support

un destacado artículo escrito por Russell: "Recent Work on the philosophy of Leibniz" (Mind, $\mathrm{n}^{\mathrm{o}} 12$, 1903, 177-201).

${ }^{21}$ Esta circunstancia también argumentaría que muchos de los textos de Ponge se muestren como borradores o cuadernos de notas, porque si cada objeto no era sino un conjunto de rasgos derivados de distintas percepciones, cada definición no podría ser sino una tentativa, un ensayo; así que ninguno de sus poemas podría aparecer como "acquis et achevé mais comme le fruit d'un travail linguistique et comme restant attaché à ce travail”" (Bracher, 1989: 177). 
d'une idée qu'il recèle [...], comme lieu de conservation des ressources émotives et des richesses de la langue, comme réservoir de méditation enfin. (Beugnot, 1986b: 135).

Así pues, y en cuanto a la elaboración de sus poemas-definiciones (conceptacles), cabrían distintas modalidades, aunque Ponge siempre establecerá, en cada uno de sus textos relativos a objetos, el conjunto de rasgos o cualidades que deberían caracterizarlos -lo que denominará sus qualités différentielles; aunque siempre teniendo en cuenta tanto sus nombres como las impresiones derivadas de las experiencias reales con las que los asociaría. $Y$ en consecuencia, si el poeta consideraba que el nombre relativo al objeto ya era adecuado, entonces los rasgos que le atribuía los deducía de su nombre; y si lo consideraba impropio, entonces acudía al conocimiento extralingüístico relativo a ese objeto en cuestión para asignarle unas cualidades del todo ajenas a ese nombre engañoso.

Asimismo, también elaboraba descripciones de objetos como si éstos no dispusieran aún de ningún nombre, por lo que el poeta actuaba entonces con plena libertad sin tener que someterse o apartarse de ningún apelativo ya impuesto, $\mathrm{y}$ proponiendo él el adecuado. Pero veamos cómo el mismo Ponge daba cuenta de todo ello:

Il s'agissait de l'objet comme notion, à laquelle contribue de façon très grave et sérieuse son nom, le mot français qui habituellement le désigne. [...] Ainsi parfois le nom m'aide, lorsqu'il m'arrive de lui inventer quelque justification ou de paraître (de me persuader) l'y découvrir. Mais il se trouve aussi parfois que cet ensemble partiel de qualités qui concerne plus le nom de l'objet que l'objet lui-même prenne un peu trop le pas sur les autres. [...] Quant aux qualités de l'objet qui ne dépendent pas tant de son nom que de tout autre chose, ma tentative d'expression de ces qualités doit se produire plutôt contre le mot qui les offusquerait, qui tendrait à les annihiler, remplacer [...], après les avoir simplifiés, pliées, condensées exagérément. Et voilà une autre façon de tenter la chose: la considérer comme non nommée, non nommable, et la décrire ex nihilo si bien qu'on la reconnaisse. Mais qu'on la reconnaisse seulement à la fin: que son nom soit un peu comme le dernier mot du texte et n'apparaisse qu'alors. Ou n'apparaisse que dans le titre (Ponge, 1971a: 35-36).

Y en este punto cabría aducir la máxima poética más celebrada de Ponge: "PARTI PRIS DES CHOSES égale COMPTE TENU DES MOTS. Certains textes auront plus de PPC à l'alliage, d'autres plus de CTM" (Ponge, 1971a: 20), porque para establecer la noción que le correspondería a cada cosa conforme a sus verdaderas qualités y con relación a su nombre, unas veces sería necesario abordar la chose desde la experiencia extralingüística (parti pris des choses, PPC); y en otras, sería más pertinente ahondar en su apelativo en el caso de que éste fuera ya óptimo (compte tenu des mots, CTM).

En resumen, el método metalógico se basaría en procedimientos intralingüísticos y en juegos verbales cuando primase el compte tenu des mots; y se decantaría por el parti pris des choses cuando fuese necesario incorporar a la definición de la chose los rasgos que se inferirían de la experiencia pragmática asociada al objeto. No obstante, las dos vías tendrían que interrelacionarse, porque la esencia del principio cratiliano supone, en definitiva, el acuerdo entre lo lingüístico y lo extralingüístico; pero en muchas ocasiones, las pautas estructurales que seguirá el poeta para describir sus objetos propiciarán ya esa doble direccionalidad: de la chose a su 
nombre (PPC), y del nombre a la chose (CTM) $)^{22}$. Veámoslo ahora a partir de distintos ejemplos: unas veces se tratará, como decíamos, de instaurar nuevas definiciones; otras, de proponer nuevos apelativos; y también habrá textos en los que el poeta considerará la pertinencia de un nombre con relación a su objeto y viceversa, como en el primer ejemplo que aducimos en donde se describe la noix:

1- Noix n'est pas loin de nœud, -naturellement... (c'est la première chose à dire) mais sortons des mots...! [...] 2- Ah! Je ne vais pas en sortir encore, puisque ce que je voulais dire ensuite (et cela me semblait tout à fait du monde concret, non des mots) est que la noix, telle qu'elle nous est présentée sur nos tables, n'est pas le fruit tout entier, mais le noyau seulement de ce fruit. Ici j'atteins la preuve de l'indifférence [...] de la pensée, du monde et de la parole. Car tout à la fois y est justifié: noix, nœud, noyau. (Ponge, 2005: 264).

En un primer momento, Ponge advierte ${ }^{23}$ una semejanza lingüística -por afinidad fonética- entre noix y nøud, pero al final del texto, el poeta argumentará su intuición postulando un vínculo entre la realidad, la lengua y el pensamiento; y así, pasa del plano lingüístico al real empírico en tanto que una circunstancia de la experiencia con el objeto (el acto de quitarle la cáscara a la fruta para ingerirla) justifica la semejanza fonética, puesto que el objeto fruta se asociará entonces a la palabra nøud con el que su apelativo (noix) había sido comparado, mediante otro de su familia (noyau) con el que el objeto real se identificaría al ser, en efecto, el núcleo (noyau) de la nuez lo que ingerimos.

Sin embargo, Ponge no siempre podrá establecer este tipo de interconexiones motivadas, pues en otro texto tendrá que lamentar que la avellana (noisette) se asemeje fonéticamente a la nuez (noix), porque consideraba que esta fruta era mucho más parecida a la bellota: "Il me semble que la noisette aurait plutôt quelque chose à voir avec le chêne (le gland du chêne) qu'avec la noix du noyer" (Ponge, 2005: 329). Y por este motivo, a menudo elaborará una nueva definición de la

${ }^{22}$ Así se extrae del exhaustivo análisis que realizó Leclair de los patrones de redacción de los poemas de Le Parti pris, pues cada objeto, situado inicialmente "dans une spatialité ou dans une temporalité", iría siendo descrito lingüística y/o empíricamente a partir de un discurso estructurado "par des particules narratives (d'abord, puis, alors, enfin)" que culminaría con la desaparición real del objeto coincidiendo ese instante con el del acabamiento mismo del poema: "le pain va être mangé, la cigarette se consume, le galet est réduit en sable" (Leclair, 1995: 77). Asimismo, el ataque del objeto en el poema podría ser directo (CTM) o indirecto (PPC). En el primer caso, "le poème commence tout de suite par la reprise du titre (nom de la chose); c'est ce qui se passe par exemple dans «Pluie», «L'Huître», «Le Mollusque», «Le Morceau de viande». Alors, la première phrase est déjà une formule et la description commence par cette phrase généralement courte qui donne une définition synthétique de la chose: phrase noyau qui va être développée dans le reste du texte" (ibid.). Y en los casos del ataque indirecto, "l'énonciation du nom de la chose est retardée [...]. Alors, le lecteur participe à une quête de la définition, l'intervalle entre le début du texte et le moment où la chose est nommée est le lieu de la métaphorisation de cette chose, par laquelle elle nous apparaît dans une singularité que son nom -renvoyant directement à l'objet ordinaire- aurait pu masquer" (ibid., 78).

${ }^{23}$ En verdad, lo apropiado sería apuntar aquí "el sujeto lírico advierte", y no "Ponge advierte", pues resulta improcedente identificar sujeto lírico con autor empírico; pero la particularidad de la poética de Ponge da coherencia a esta elemental identificación, pues del mismo modo que el poeta postula que el signo table, por ejemplo, es la chose table, sin reparos se inmiscuye como persona biográfica-que no como personalidad poética- en sus escritos. 
chose - pero partiendo siempre de su nombre- a fin de operar las rectificaciones que juzgue oportunas para poder evidenciar la motivación. Así sucederá, por ejemplo, con las fourmis, que Ponge definirá como "Fourmillement de formes à têtes d'épingles rouges" (Ponge, 2005: 389) para justificar, por semejanza fonética, el nombre del insecto a partir del movimiento nervioso que adoptan, en la realidad extralingüística, las hileras de hormigas. $\mathrm{O}$ bien, podría atribuir al objeto alguna característica específica -o incluso inventada- en función de lo que se derivase de su apelativo, por lo que señalará, a propósito de las ombelles, por ejemplo, que "ne font pas d'ombre, mais de l'ombe" (Ponge, 2003: 50): es decir, inscribiendo aquí un neologismo por síncopa - pues se elidiría la /r/ de la voz ombre- para hacer derivar, por justificación fonética, ombe de ombelle.

En cuanto a la tarea de modificar o remodelar los nombres de las cosas para que reflejen con pertinencia el objeto que designan, Ponge dirá de las hirondelles, por ejemplo, que deberíamos llamarlas, más propiamente, "Flammèches [...] (je veux dire à la fois flamme et flèche)" (Ponge, 2003: 165); y ello debido a que surcarían el cielo atravesándolo como las flechas, y porque el poeta siempre percibió las alas de las aves y las de los insectos como si fueran llamas. Pero también propondrá el denominativo horizondelles en virtud de que las golondrinas no sólo surcan el cielo, sino también el horizonte; y además, como se establece una coincidencia virtual entre el sonido -elle(s) y el que se correspondería con -aile(s), el término horizondelles remitirá, en consecuencia, a un 'horizonte alado', a un horizonte de golondrinas si tomamos el signo ala como sinecdóquico de pájaro. Y otro ejemplo ilustrativo podría ser el de la grenouille: el autor primero establece un neologismo por derivación: de grenouille a grenouillerie; y acto seguido, se refiere al mismo anfibio mediante otro neologismo que sería el resultado de la fusión entre los sustantivos amphibie y ambiguïté: amphibiguïté (Ponge, 1967: 33), porque un anfibio es, en efecto, ambiguo en tanto que puede vivir en la tierra y en el agua.

No obstante, también podría suceder que ya la chose poseyera su óptima denominación, así que una tarea en torno a la mimosa, por ejemplo, se le presentaba al poeta como impracticable, puesto que, a su juicio, el nombre del objeto era ya el idóneo:

ce qui rend si difficile mon travail, est-ce que le nom du mimosa est déjà parfait. Connaissant l'arbuste et le nom du mimosa, il devient difficile de trouver mieux pour définir la chose que ce nom même (Ponge, 1952: 63).

$\mathrm{Y}$ en este caso, la relación entre el objeto y su nombre se argumentaría por simbolismo fonético, dado que la suavidad de la bilabial reiterada $/ \mathrm{m} /$ podría evocar la flor de la mimosa por cuanto las propiedades sensibles de ésta son muy similares a las de la fibra del algodón. Además, Ponge insistirá en el vínculo nombre-objeto mediante unos acrósticos, pues aducirá que las boulettes du mimosa emiten lo siguente: "MIraculeuse /MOmentanée /SAtisfaction // Minute /MOusseusse /SAfranée!" (Ponge, 1852: 64).

Asimismo, el poeta recurrió también a la etimología para justificar la idoneidad de los nombres. Y así, comentándole a Sollers el siguiente verso de un soneto de Malherbe: Il n'est rien de si beau comme Calixte est belle, Ponge celebró que "tout 
le poème est une pure tautologie", porque, en efecto, Calixte deriva del griego Kallistos, superlativo de Kalós, 'bello': "Calixte signifie déjà, étymologiquement, la plus belle [...]. La beauté est la beauté, [...] et il ne s'agit que de développer cela... cette tautologie, qui est, au fond, contenue seulement dans le nom" (Sollers, 1970: 190-191). Y es que la indagación etimológica será una de las tareas más frecuentes de la métalogique pongeana así como también lo había sido para los seguidores de la tesis naturalista en el Crátilo, porque como el paso del tiempo habría obrado cambios sobre las formas primigenias de las palabras, explorar el origen de éstas nos conduciría a descubrir sus verdaderos significados (y ya la raíz griega etymosignifica 'real', 'verdadero'); un hecho que nos revelaría, además, la auténtica naturaleza de los objetos, aquella por la que a cada uno de ellos se le habría asignado su justo nombre.

Por lo tanto, y con respecto a l'assiette, por ejemplo, Ponge referirá que "le nom de sa belle matière d'un coquillage fut pris. [...] On la nomma porcelaine, [...] vulve de truie" (Ponge, 2003: 123), porque el término porcelana -material del que, supuestamente, estaría fabricado el plato que describía el poeta- significaba, propiamente, 'cauri, molusco de caparazón blanco y brillante' (motivo por el que se aplicó a la loza fina que, originaria de China, fue imitada en toda Europa, dado que se creía que se elaboraba con el caparazón pulverizado del molusco). Y de ahí que Ponge incorporase a su poema las cualidades de ese material con el fin de describir su objeto del modo más exacto posible: "gardons-nous de nacrer trop cet objet de tous les jours. Nulle ellipse prosodique, si brillante qu'elle soit" (ibid.) [las cursivas son nuestras]. Y con respecto a la guêpe, el poeta se referirá a ella en tanto que Hyménoptère (término de entomología que identifica la clase de insectos de cuatro alas membranosas), aunque lo hará cuestionándose la idoneidad del denominativo al preguntarse si "l'hymen des jeunes filles ressemble à vrai dire beaucoup à l'aile des guêpes" (Ponge, 1952: 17), porque del griego hymēn -énos ('membrana') provendría el nombre de la fibra membranosa de la vagina virginal.

Con todo, cabe precisar que la tarea etimológica en Ponge nunca fue de rigurosa investigación lingüística, porque más que interesarle el verdadero origen de las palabras, trataba de hallar aquellos síntomas que pudieran argumentarle la relación motivada entre un nombre y su objeto. Como bien apuntó Beugnot (1986a: 165) a propósito de las etimologías pongeanas, "ce n'est pas l'histoire de la langue qui attire Ponge; après tout il se préoccupe moins d'exactitude [...] que d'heureuses rencontres et d'une secrète téléologie où s'accomplit la destinée commune des choses et des mots", así que, de hecho, podríamos relacionar el planteamiento etimológico de Ponge con el llevado a cabo por Varrón en De lingua latina, ya que el proceder etimológico que allí desarrolló el autor de Rieti "ne s'intéresse pas au langage en soi mais au langage en tant que représentant le monde. D'où le plan de son travail fondé sur une classification des choses et non sur des critères linguistiques" (Desbordes, 1984: 150).

En conclusión, aimer les choses implicaría, para Ponge,

aimer aussi ces noms. Les aimer assez -comme tels- que nous puissions à nouveau tenter de les faire se rencontrer (choses et noms), rentrer les uns dans les autres (choses et noms). L'amour des mots est donc en quelque façon nécessaire à la jouissance des choses (Ponge, 1971b: 25); 
y esta jouissance, además, no sólo nos remitiría al neologismo pongeano del objeu -voz que aglutinaría objet y jeu, y que haría referencia a su quehacer metalógico ${ }^{24}-$, pues teniendo en cuenta la admiración siempre confesada de Ponge hacia Mallarmé (Sollers, 1970: 32), la expresión podría recordarnos, aunque en sentido contrario, a la jouissance del conocido texto mallarmeano de la respuesta a "Sur l'évolution littéraire" (1891); a aquel en donde el autor de Igitur expresaba que

Nommer un objet, c'est supprimer les trois quarts de la jouissance du poème qui est faite de deviner peu à peu: le suggérer, voilà le rêve. C'est le parfait usage de ce mystère qui constitue le symbole: évoquer petit à petit un objet pour montrer un état d'âme, ou, inversement, choisir un objet et en dégager un état d'âme par une série de déchiffrements [...]. Il doit y avoir toujours énigme en poésie, et c'est le but de la littérature, -il n'y en a pas d'autres-d'évoquer les objets. (Mallarmé, 1945: 869).

Pero como adelantábamos, este enfoque sería justo el opuesto al pongeano, porque con su cratilismo, lo que pretendía Ponge no era évoquer sino mostrar, y no suggérer sino certificar: es decir, explicitar el fehaciente vínculo que para él existiría entre el significado de un objeto y su denominativo en función del "sentiment (l'intuition) que la nomination est la clef du tout" (Ponge, 1971b: 26). Así pues, y como anotó Calvino, la operación de Ponge tendría que situarse "sullo stesso piano di quella de Mallarmé”, pero

in direzione divergente e complementare: in Mallarmé la parola raggiunge l'estremo dell'esattezza toccando l'estremo dell'astrazione e indicando il nulla come sostanza ultima del mondo; in Ponge il mondo ha la forma delle cose più umili e contingenti e asimmetriche e la parola è ciò che serve a render conto della varietà infinita di queste forme irregolari e minutamente complicate (Calvino, 1993: 84).

Y es que, tal y como se lo refirió Crátilo a Sócrates, "el que conoce los nombres, conoce también las cosas" (Crátilo, 435e): lo que significó, para Ponge, que tomar partido por las cosas (parti pris des choses) implicaba tener en cuenta las palabras (compte tenu des mots).

\section{REFERENCIAS BIBLIOGRÁFICAS}

Agustín, S. (1997): De doctrina christiana/La doctrine chrétienne. Euvres de Saint Augustin (lème série), intr. y trad. de M. Moreau, texto y notas de I. Bochet y G. Madec, Institut d'Études Augustiniennes, Paris.

BARTHES, R. (2004): "Proust et les noms", in Le degré zéro de l'écriture suivi de Nouveaux essais critiques, Seuil, Paris, 118-130.

Benveniste, É. (1966): Problèmes de linguistique générale, vol. I, Gallimard, Paris. Beugnot, B. (1986a): "Francis Ponge et l'invention des formes", Cahiers d'Histoire des Littératures Romanes, $\mathrm{n}^{\circ}$ 1-2, Heidelberg, 154-170.

\footnotetext{
${ }^{24}$ En efecto, Ponge apuntaba que "Il y a dans Le Parti pris une déprise, une désaffection à l'égard du casse-tête métaphysique... par création HEUREUSE du métalogique" (Ponge, 1967: 196); y de igual modo creó el neologismo objoie en tanto que la joyeuse métalogique sería "vraiment heureuse, jubilante" (Sollers, 1970: 190).
} 
(1986b): "Une poésie du manifeste?", in Francis Ponge. Cahier de L'Herne, no 51, dir. de J.-M. Gleize, L’Herne, Paris, 122-142.

Bonnefis, Ph./Oster, P. (dirs.) (1977): Ponge inventeur et classique. Colloque de Cerisy, Union Générale d'Éditions, Paris.

BRACHER, N. (1989): "Pour ouvrir des abîmes: les textes in-finis de Francis Ponge", Romance Quarterly, vol. 36, $\mathrm{n}^{\circ}$ 2, 169-178.

Braque, G. (1952): Le Jour et la Nuit. Cahiers 1917-1952, Gallimard, Paris.

CAlvino, I. (1993): Lezioni americane. Sei proposte per il prossimo millennio, Mondadori, Milano.

Claudel, P. (1965): Euvres en prose, ed. y notas de J. Petit y Ch. Galpérine, prefacio de G. Picon, Gallimard, col. "Bibliothèque de la Pléiade", Paris.

— (1967): Cuvre poétique, intr. de S. Fumet, ed. y notas de J. Petit, Gallimard, col. "Bibliothèque de la Pléiade", Paris.

DAHLIN, L. A. (1980): "Entretien avec Francis Ponge: ses rapports avec Camus, Sartre et d'autres" [entrevista realizada a Ponge en 1979], The French Review, vol. LIII, ${ }^{\circ}$ 2, 271-281.

DESBORDES, F. (1984): “Actes de langage chez Varron?”, in Matériaux pour une histoire des théories linguistiques, ed. de S. Auroux et al., Université de Lille, Lille, 147-153.

FARASSE, G. (1977): "Quelques phrases mises de côté pour Francis Ponge", in Ponge inventeur et classique. Colloque de Cerisy, dir. de Ph. Bonnefis y P. Oster, Union Générale d'Éditions, Paris, 199-220.

(1996): L'âne musicien. Sur Francis Ponge, Gallimard, Paris.

GEFEN, A. (ed.), (2002): La mimèsis, Flammarion, Paris.

GenetTe, G. (1976): Mimologiques. Voyage en Cratyle, Seuil, Paris.

GioRDAn, C. (1976): "Ponge et la nomination", Poétique, no 8, 484-495.

GLEIZE, J.-M. (1988): Francis Ponge, Seuil, Paris.

KleIBeR, G. (1981): Problèmes de Référence. Descriptions définies et noms propres, Librairie Klincksieck, Paris.

KristeVA, J. (1981): Le langage, cet inconnu. Une initiation à la linguistique, Seuil, Paris.

LECLAIR, D. (1995): Lire "Le Parti pris des choses", Dunod, Paris.

LÉvY, S. (1993): "Mutisme pongien et chose mallarméenne", Dalhousie French Studies, $\mathrm{n}^{\circ}$ 25, 79-88.

(1999): Francis Ponge. De la connaissance en poésie, PUV, Vincennes.

LitTLE, R. (1992): "Francis Ponge et la nostalgie cratylienne", Europe, no ${ }^{\circ} 755$, 32-38.

LiTTRÉ, É. (2000): Dictionnaire de la langue française (1863-1873), Redon, Marsanne (versión en CD-ROM).

LUCRECIO CARO, T. (1983): De la naturaleza/De rerum natura, vol. II, texto revisado y trad. de E. Valentí, CSIC, Madrid.

LuebBers, M.-H. (2007): "La Cruche de Ponge: un objeu mallarméen", The French Review, vol. 80, $\mathrm{n}^{\mathrm{o}} 4,860-877$.

MaldineY, H. (1993): Le vouloir dire de Francis Ponge, Encre marine, Fougères-La Versanne.

MALMBERG, B. (1977): Signes et symboles, Picard, Paris. 
MallarmÉ, S. (1945): Euvres complètes, ed. y notas de H. Mondor y G. Jean-Aubry, Gallimard, col. "Bibliothèque de la Pléiade", Paris.

Platón (1987): Diálogos. Gorgias, Menéxeno, Eutidemo, Menón, Crátilo, vol. II, trad. intr. y notas de J. Calonge Ruiz, E. Acosta Méndez, F. J. Olivieri y J. L. Calvo, Gredos, Madrid.

Ponge, F. (1952): La Rage de l'expression, Mermod, Lausanne.

- (1965): Pour un Malherbe, Gallimard, Paris.

(1967): Le Parti pris des choses, suivi de Proêmes, Gallimard, Paris.

(1971a): Méthodes, Gallimard, Paris.

(1971b): La Fabrique du Pré, Skira, Genève.

(1999): CEuvres complètes, vol. I, ed. de B. Beugnot con la colab. de M. Collot, G.

Farasse, J.-M. Gleize, J. Martel, R. Mélançon y B. Veck, Gallimard, col. "Bibliothèque de la Pléiade", Paris.

(2002): Euvres complètes, vol. II, ed. de B. Beugnot con la colab. de G. Farasse, J.-M. Gleize, J. Martel, R. Mélançon, Ph. Met y B. Veck, Gallimard, col. "Bibliothèque de la Pléiade", Paris. (2003): Pièces, Gallimard, Paris.

(2005): Pages d'Atelier 1917-1982, comp., ed. y pres. de B. Beugnot, Gallimard, Paris.

POP, I. (1988): “C'est très jeune que j'ai commencé à ouvrir le dictionnaire" [entrevista realizada a Ponge en 1976], Digraphe, $\mathrm{n}^{\circ} 46,11-21$.

REY, A. (1973): Théories du signe et du sens. Lectures I, Klincksieck, Paris.

SARTORIS, G. (1989): "De la modification des choses par la parole", Nouvelle Revue Française, no $433,75-79$.

SAUSSURE, F. de (1974): Cours de linguistique générale (publié par Charles Bally et Albert Sechehaye, avec la collaboration de Albert Riedlinger), ed. de Tullio de Mauro. Payot, Paris.

SCHAEFFER, J.-M. (1980): "Romantisme et langage poétique", Poétique, $\mathrm{n}^{\circ}$ 42, 177194.

SOLLers, Ph. (1970): Entretiens de Francis Ponge avec Philippe Sollers [doce entrevistas realizadas en 1967], Gallimard/Seuil, Paris.

SPADA, M. (1988): "Une parole à l'état naissant" [entrevista realizada a Ponge en 1979], Magazine littéraire, $\mathrm{n}^{\circ}$ 260, 26-33.

VAletTe, B. (1988): "Les mots et les choses: le point de vue du linguiste", in VVAA, Analyses et réflexions sur Ponge, Marketing, Paris, 23-29.

VARRÓN, M.T. (1990): De lingua latina/Sobre la lengua latina, intr., trad. y notas de M.-A. Marcos Casquero, Anthropos-MEC, Barcelona.

ViÑAS DEL PALACIO, Y. (2003): "Du sacrifice des mots à l'avènement de la parole: $L a$ Figue (sèche) de Francis Ponge", Thélème. Revista Complutense de Estudios Franceses, $\mathrm{n}^{\mathrm{o}}$ 18, 123-132.

WITTGENSTEIN, L. (1988): Investigaciones filosóficas/Philosophische Untersuchungen, trad. de A. García Suárez y U. Moulines, Crítica/Instituto de Investigaciones Filosóficas. Universidad Nacional Autónoma de México, Barcelona/México. 